\title{
Parents Do Matter: Trajectories of Change in Externalizing and Internalizing Problems in Early Adolescence
}

\author{
Nancy L. Galambos, Erin T. Barker, and David M. Almeida
}

\begin{abstract}
This study examined the relative influence of three parenting behaviors (support, behavioral control, and psychological control) and deviant peers on trajectories of externalizing and internalizing problems in early adolescence. A white, working-to-middle-class sample of adolescents and their mothers and fathers in twoearner families participated in a $3 \frac{1}{2}$-year longitudinal study ( $N=109$ families). The study began when the adolescents were in sixth grade $(\mathrm{M}$ age=11.5 years). Analyses showed that parents' firm behavioral control seemed to halt the upward trajectory in externalizing problems among adolescents with deviant peers. Initial levels of internalizing problems were higher among adolescents with parents who reported lower levels of behavioral control and among adolescents with deviant peers. This study suggests that parenting exerts an important influence in adolescents' lives and may do so even in the face of potentially negative peer influence.
\end{abstract}

Several decades of research on parent-child relations has led to the identification of three global, relatively independent dimensions of parental behavior: support (responsiveness and connectedness to the child), behavioral control (regulation of the child's behavior through firm and consistent discipline), and psychological control (control of the child's behavior through psychological means such as love withdrawal and guilt induction); (Barber, Olsen, \& Shagle, 1994; Maccoby \& Martin, 1983; Schwarz, BartonHenry, \& Pruzinsky, 1985). Although each of these parenting behaviors has been linked with indicators of adolescents' behavior and psychosocial adjustment (Barber et al., 1994; Forehand \& Nousiainen, 1993), there is a very limited body of research examining all three parenting behaviors in the same study as unique predictors of adolescent development. Thus, an important goal of this study was to understand the relative and unique influence of support, behavioral control, and psychological control on specific aspects of adolescent adjustment (Barber, 1997).

A second major issue concerns the combined influence of parents and peers on adolescent development. Recent (and controversial) arguments pose the question: Do parents matter? (Harris, 1995). After all, there is a strong and well-established link between

Nancy L. Galambos and Erin T. Barker, Department of Psychology, University of Alberta; David M. Almeida, Division of Family Studies, University of Arizona.

This research was supported by a Social Sciences and Humanities Research Council of Canada grant to the first author. The authors acknowledge the participation of the families who participated in this project.

Correspondence concerning this article should be addressed to Nancy L. Galambos, Department of Psychology, P217 Biological Sciences Bldg., University of Alberta, Edmonton, AB T6G 2E9, Canada. Electronic mail may be sent to galambos@ualberta.ca. adolescents' association with deviant peers and externalizing problems such as drug use and delinquency (Brendgen, Vitaro, \& Bukowski, 2000). The focus of most contemporary developmental psychologists, however, is on how parents and peers jointly influence adolescents (Collins, Maccoby, Steinberg, Hetherington, \& Bornstein, 2000). Therefore, in this study, we examined how parenting (parental support, behavioral control, and psychological control) and the deviant peer context are related to concurrent and changing levels of individuals' externalizing (e.g., smoking, shoplifting) and internalizing (e.g., depressive symptoms) problems over several years. These relations were observed from early to middle adolescence because it is during this period of multiple, interrelated physical, social, and cognitive changes and increasing levels of behavioral autonomy that young people become vulnerable to the potential negative influences of peers, typically show an increase in some externalizing behaviors, and may first experience internalizing problems (Maggs, Almeida, \& Galambos, 1995; Moffitt, 1993; Petersen et al., 1993). Moreover, early adolescence is a sensitive period for parents because they must learn to facilitate appropriate levels of autonomy in their children, relax some control, and remain supportive during a demanding transition (Galambos \& Ehrenberg, 1997). The extent to which parents are successful in meeting these challenges may influence how well adolescents adjust to the many changes they experience.

\section{Parenting Dimensions and Adolescent Adjustment}

The examination of parental support, behavioral control, and psychological control as independent (C) 2003 by the Society for Research in Child Development, Inc. All rights reserved. 0009-3920/2003/7402-0017 
predictors of adolescent adjustment is important for several reasons. First, studies that have examined two or three of the parenting behaviors reveal interesting differential associations of parenting with adolescent adjustment (Barber, 1997). For example, when compared with psychological control or support, higher behavioral control has been linked consistently with lower levels of externalizing problems such as substance use, antisocial behavior, and delinquency (Barber \& Olsen, 1997; Eccles, Early, Frasier, Belansky, \& McCarthy, 1997; Garber, Robinson, \& Valentiner, 1997; Gray \& Steinberg, 1999; Herman, Dornbusch, Herron, \& Herting, 1997; Pettit, Laird, Dodge, Bates, \& Criss, 2001). On the other hand, higher psychological control has been associated with internalizing problems such as depressed mood (Barber et al., 1994; Garber et al., 1997; Gray \& Steinberg, 1999; Pettit et al., 2001). Moreover, there is growing evidence that psychological control is also related positively to externalizing problems (Barber, 1996; Barber \& Olsen, 1997; Eccles et al., 1997). Thus, psychological control seems to be more broadly related to adolescent problems than is behavioral control.

With respect to the role of parental support vis-àvis behavioral and psychological control, two studies have found that higher support, higher behavioral control, and lower psychological control were related significantly to higher academic competence (Eccles et al., 1997; Gray \& Steinberg, 1999). In a similar study, Herman et al. (1997) reported that support was related to higher grades, but lost to behavioral and psychological control in regressions used to predict other adolescent outcomes such as substance use. In their inclusive model, Garber et al. (1997) reported that both lower support and higher psychological control were linked with adolescent depression. Another study found that when parental support, behavioral control, and psychological control were examined simultaneously, support was linked negatively and strongly to externalizing and internalizing problems in adolescents, and behavioral control was not associated with either problem (Fauber, Forehand, Thomas, \& Wierson, 1990). Others (Costigan, 1996; Forehand \& Nousiainen, 1993) have also found that parental support was a primary predictor of adolescents' adjustment, relative to psychological or behavioral control. Some authors have suggested that parental support facilitates adolescents' feelings of psychological wellbeing, gives them confidence, and leads generally to social and academic competence (Barber, Maugahn, Olsen, \& Thomas, 2002; Gray \& Steinberg, 1999).
Second, scholars have argued for the usefulness of typologies of parenting styles that consist of the aggregation of parenting behaviors (Baumrind, 1991; Maccoby \& Martin, 1983). For example, different combinations of support and behavioral control have been used to operationalize four parenting styles: authoritative (high support/high control), authoritarian (low support/high control), indulgent (high support/low control), and neglectful (low support/low control); (Lamborn, Mounts, Steinberg, \& Dornbusch, 1991; Slicker, 1998; Steinberg, Lamborn, Darling, Mounts, \& Dornbusch, 1994). Such typologies assume that there are interactions among the parenting behaviors that constitute the types (e.g., Support $\times$ Behavioral Control), yet not all studies have tested this assumption (e.g., Lamborn et al., 1991; Steinberg et al., 1994). In those that have, significant interactions largely have failed to materialize (Barber et al., 1994; Garber et al., 1997; Herman et al., 1997; Kurdek \& Fine, 1994; Kurdek, Fine, \& Sinclair, 1995; Stice, Barrera, \& Chassin, 1993; see Forehand \& Nousiainen, 1993, for an exception). These results cast doubt on the validity of the parenting typologies and suggest that it is crucial to disaggregate and investigate the separate dimensions that constitute overall parenting style (Barber, 1997; Herman et al., 1997). Moreover, because so few studies have examined whether support, behavioral control, and psychological control interact in the prediction of adolescent adjustment, it is important to conduct systematic testing of such interactions (Barber, 1997). In so doing, a more accurate and comprehensive picture will be obtained of the ways in which parenting behaviors are linked to adolescent adjustment.

A third reason for considering the three parenting behaviors simultaneously is to allow for the examination of curvilinear relations between behavioral control and adolescent adjustment. Authors have proposed that moderate levels of parental behavioral control are best for adolescents' psychosocial adjustment, with high and low levels least effective (Rollins \& Thomas, 1979). Although several studies have found curvilinear effects, results have been inconsistent. There has been some support for the "moderate control is best" hypothesis (Kurdek et al., 1995; Mason, Cauce, Gonzales, \& Hiraga, 1996; Miller, McCoy, Olson, \& Wallace, 1986; Stice et al., 1993), but others have reported steep increases in adolescents' psychosocial competence at the upper levels of control (Costigan, 1996; Kurdek \& Fine, 1994). Clearly, further research is needed to test for and describe the specific nature of curvilinear relationships. 
Shortcomings in Research on Parenting and Adolescent Adjustment

A shortcoming of previous work on parenting behaviors and adolescents' adjustment is heavy reliance on adolescents' self-reports as indicators of parents' behaviors and adolescents' own problems (e.g., see Barnes, Reifman, Farrell, \& Dintcheff, 2000; Gray \& Steinberg, 1999; Stice et al., 1993). This practice creates a common method variance problem due to the use of a single reporter and, hence, may exaggerate the true relations between parenting and adolescent adjustment. Some researchers have avoided the common method variance problem by using combined mother-adolescent data (Barber et al., 1994) or by obtaining measures of adolescent adjustment from independent reporters (Kurdek et al., 1995; Mason et al., 1996). In the current study, combined reports from mothers and fathers were used to measure parenting behavior, whereas adolescents' reports were used to assess their externalizing and internalizing problems.

Another gap in the research to date is the dearth of longitudinal data examining the links between these three dimensions of parenting and adolescent problems over time. Studies finding contemporaneous links between dimensions of parenting and adolescent adjustment are limited because it is impossible to sort out whether a significant correlation is due to the parent's influence on the adolescent, the adolescent's influence on the parent, or a third variable. Only through longitudinal studies that control for initial levels of adolescent adjustment can conclusions be drawn about the potential longer term effects of parenting on adolescents (Collins et al., 2000). Longitudinal studies of parenting and adolescent development typically have examined changes in adolescents' behaviors at only two time points (Barber, 1996; Herman et al., 1997; Mason et al., 1996; Steinberg et al., 1994; Stice \& Barrera, 1995). Studies limited to two time points, however, are unable to provide precise and reliable estimates of intraindividual change. Multiwave, multiyear studies, on the other hand, enable the precise modeling of individual growth trajectories, determination of the rates of change in behavior, and investigation of predictors of interindividual differences in intraindividual change (Bryk \& Raudenbusch, 1992; Willett, 1989).

In an exemplary multiwave study that followed 13- to 16-year-old adolescents over a 7-year period, Barnes et al. (2000) demonstrated that parents' higher behavioral control at Wave 1 was linked both with low initial (Wave 1) levels of alcohol misuse in adolescents and with a dampening of the typical upward trajectory of alcohol misuse that occurs in adolescence. Similarly, Simons, Chao, Conger, and Elder (2001) used four waves of data to show that inept parenting (low monitoring, harsh discipline, hostility) increased adolescents' affiliation with deviant peers and their delinquent behavior across a 4-year period. In the current study, longitudinal data collected at five waves across the period of early adolescence were used to examine how parenting in Grade 6 influenced trajectories of adolescent problems.

\section{Parenting Influences in the Context of Peers}

Recent longitudinal studies show that adolescents with deviant peers engaged in higher levels of externalizing behavior (Mason et al., 1996; Scaramella, Conger, Spoth, \& Simons, 2002; Simons et al., 2001). Moreover, there was an association between having deviant friends and the presence of internalizing problems (i.e., depression; Brendgen et al., 2000). These studies also show that the relation between deviant peers and adolescent adjustment depended on the quality of parenting. For example, low parental support and low behavioral control had direct influences on adolescents' higher levels of externalizing problems (e.g., aggression, disruptiveness; Kim, Hetherington, \& Reiss, 1999; Pettit et al., 2001; Scaramella et al., 2002). There were also indirect effects of parenting behaviors that operated through their impact on adolescents' associations with deviant peers. Specifically, poorer parenting (e.g., low involvement) increased the probability that adolescents would affiliate with deviant peers, and more association with deviant peers, in turn, was related to externalizing problems such as delinquency (Kim et al., 1999; Mason et al., 1996; Scaramella et al., 2002; Simons et al., 2001). Given the importance of peers as contributors to adolescent behavior, in the present study, the relative influences of parental support, behavioral control, and psychological control on adolescent adjustment were considered along with the influence of deviant peers.

\section{The Present Study}

In the current investigation, all three parenting dimensions were examined as predictors of adolescents' externalizing and internalizing problems using data from a study that followed adolescents in two-parent families five times across a 3.5-year period (Grade 6 to the summer following Grade 9). Hierarchical linear modeling (HLM; Bryk \& 
Raudenbusch, 1992) was used for this purpose. The impact of initial (Grade 6) parenting behaviors on the initial level of adolescents' externalizing and internalizing problems as well as on trajectories of change in these problems was examined. Following previous investigations (e.g., Barber et al., 1994; Barnes et al., 2000), we expected that parents' higher behavioral control would be linked with lower initial levels of and a dampening of the typical increase in externalizing problems across adolescence whereas parents' higher psychological control would be linked with higher initial levels of and an upward increase in both externalizing and internalizing problems. Given the literature on the role of parental support, we expected that support would be linked inversely with externalizing and internalizing problems. The current study also tested all two-way interactions among the three parenting behaviors in the prediction of adolescents' problems, as well as the curvilinear effect of behavioral control on these problems.

To examine parenting behavior in the context of peers, adolescents' reports of deviant peer associations were used to disentangle (a) the concurrent effects of Grade 6 parenting and deviant peers on initial levels and trajectories of change in adolescents' problems, and (b) the effects of Grade 6 parenting on initial levels and trajectories of change in adolescents' problems, controlling for deviant peers at all occasions. We hypothesized that despite an expected positive relation between deviant peers and adolescents' problems, some parenting behaviors would emerge as significant in the prediction of initial levels and trajectories of change in adolescents' problems (e.g., see Kim et al., 1999; Scaramella et al., 2002). Finally, interactions between deviant peers and the parenting behaviors in the prediction of initial levels and trajectories of change in adolescents' externalizing and internalizing problems were investigated. Based on the findings of previous research (e.g., Mason et al., 1996), it was expected that among adolescents with deviant peers, parents' high behavioral control would halt the typical upward trajectory in externalizing problems.

\section{Method}

\section{Participants}

The participants were adolescents, mothers, and fathers who participated in a 3.5-year longitudinal study of White, two-parent families in which both parents were employed (the Two-Earner Family Study; Galambos \& Maggs, 1991). The study began with 112 adolescents (62 girls, 50 boys) who were in Grade $6(M$ age $=11.5$ years, $S D=.42)$ at the first time of measurement. Data were collected on five occasions: winter 1988 (Time 1), summer 1988 (Time 2), winter 1989 (Time 3), summer 1990 (Time 4), and summer 1991 (Time 5).

With respect to the occupations held by the parents, $25 \%$ of fathers were in professional/technical occupations; $35 \%$ were in managerial, sales, or clerical occupations; and 39\% were in service, unskilled, or skilled labor occupations. Corresponding figures for mothers were $18 \%, 73 \%$, and $10 \%$, respectively. Mean family socioeconomic status (SES) was $50.01(S D=15.18)$, as assessed by the father's score on the Blishen and McRoberts (1976) occupational index for Canadian samples. Examples of occupations and their SES scores are motor vehicle repair (32.8), real estate sales (50.1), and accounting (67.4). Thus, the sample is characterized largely as working to middle class.

The mothers of the participants worked for an average of 30.9 hours per week $(S D=11.2)$, and fathers worked an average of 42 hours per week $(S D=10.3)$. The mothers had been employed for an average of 6.5 years $(S D=5.4)$; fathers had been employed an average of 17.2 years $(S D=7.4)$. The mean number of children per family was 2.4 $(S D=0.9)$, and the mean number of years married was $14.7(S D=4.5)$. Mothers and fathers had achieved similar levels of education (mothers: $M=13.1$ years, $S D=2.2$; fathers: $M=13.8$ years, $S D=3.1)$. The mean age of the mothers was 37.4 years $(S D=3.9)$ and the mean age of fathers was 40 $(S D=5.5)$.

\section{Procedure}

At each time of measurement, questionnaires were mailed individually to each family member to complete and return by mail. Participants were asked not to discuss the questionnaires with one another and were given separate return envelopes. As an additional reassurance of confidentiality, questions pertaining to adolescents' externalizing behaviors were printed and collated separately, and an extra envelope was provided in which to seal these questions on completion. Each participant received a token payment after participating (increasing from $\$ 5$ at Time 1 to $\$ 15$ at Time 5).

Of the 112 families in the study, three were excluded because of missing data, leaving a sample size of 109. The percentages of original participants providing data at each time of measurement were: Time $2(94 \%, n=103)$, Time $3(83 \%, n=91)$, Time 4 
$(70 \% ; n=76)$, and Time $5(69 \% ; n=75)$. Time was coded as the number of years that had passed since the first occasion of measurement, thus reflecting the uneven spacing of the intervals between occasions. Specifically, time was coded as: Time $1(0)$, Time 2 (.5), Time 3 (1), Time 4 (2.5), and Time 5 (3.5). Participants who dropped out of the study did not differ from those who remained with respect to demographic variables (e.g., education, age, SES). Mothers and fathers who dropped out did not differ from parents who remained on initial levels of all three parenting behaviors. As well, adolescents who dropped out did not differ from those who stayed in the study on initial levels of externalizing or internalizing problems and deviant peers.

\section{Measures}

Parenting. Time 1 scores on the parent version of the 56-item Child's Report of Parental Behavior Inventory (CRPBI; Burger \& Armentrout, 1971; Schaefer, 1965) were used to assess mothers' and fathers' perceptions of their own support, behavioral control, and psychological control in relation to their adolescent. The support measure consisted of the mean of 24 items (e.g., "I almost always speak to our child in a warm and friendly voice") rated on a 5point scale ranging from 1 (very much unlike me) to 5 (very much like me). We expanded the original 3-point response scale to increase variability. Cronbach's alphas were .92 for fathers and mothers. The behavioral control measure consisted of the mean of 16 items (reverse scored) (e.g., "I let our child get away with a lot of things"; "I let our child stay up late if he/she keeps asking"), also rated on the 5point scale. Cronbach's alphas were .80 for fathers and .84 for mothers. The psychological control measure consisted of the mean of 15 items (e.g., "I say that someday our child will be sorry that he/she wasn't better as a child"; "I think our child is not grateful when he/she doesn't obey") rated on a 5point scale (typically 16 items long; one item was omitted at the request of school officials). Cronbach's alphas were .87 for fathers and .85 for mothers. The reliability and validity of these subscales are well established (Schwarz et al., 1985).

To combine mothers' and fathers' reports, the mean of mothers' and fathers' scores on each scale was calculated. Mothers' and fathers' reports were combined because of evidence that aggregate scores on these measures decrease systematic error variance and increase validity (Schwarz et al., 1985). The alphas for the combined scales were high $(.93, .81$, and .87 for support, behavioral control, and psycho- logical control, respectively). Moreover, the mean difference between mothers' and fathers' reports was $-.23,-.04$, and .15 for support, behavioral control, and psychological control, respectively. Close to $90 \%$ of the mother-father pairs differed by no more than 1 point on the 5-point scale. Thus, the practice of combining the scores in this sample did not average out extreme differences. There were six cases in which mother-only scores were used because fathers' data were missing. There was one case in which father-only scores were used because mothers' data were missing.

Deviant peers. At each of Times 1 through 5, the mean of four items (Galambos \& Maggs, 1991) was used to assess the extent to which the adolescent's friends engaged in misconduct or problem behavior, such as shoplifting or damaging property. These items (e.g., 'My friends often get into trouble with adults"; "Some of my friends break other people's things for fun") were rated on a 4-point scale ranging from 1 (disagree strongly) to 4 (agree strongly). Cronbach's alpha ranged from .69 to .78 across the five occasions of measurement. Higher scores on this measure have been linked with adolescents' higher levels of problem behavior and lower levels of parental support (Galambos \& Maggs, 1991; Galambos, Sears, Almeida, \& Kolaric, 1995).

Externalizing problems. At Times 1 through 5, externalizing problems were measured with the mean of eight items from the Brown, Clasen, and Eicher (1986) misconduct scale and an additional 16 items from the Kaplan (1978) deviant response scale. Adolescents were asked "how many times in the past month" they had engaged in 24 behaviors, rated on a 5-point scale ranging from 1 (never) to 5 (almost every day). The items covered a range of behaviors including disobedience to parents (e.g., "done something that your parents told you not to do"), school misconduct (e.g., "been suspended or expelled from school"), substance use (e.g., "smoked marijuana"), and antisocial behavior (e.g., "damaged or destroyed public or private property on purpose"). Cronbach's alphas ranged from .77 to .90 across the five times of measurement. Higher scores on this measure (indicating more problem behavior) were correlated significantly with lower levels of impulse control and mastery, and higher levels of peer involvement and association with deviant peers (Galambos \& Maggs, 1991; Galambos et al., 1995).

Internalizing problems. At Times 1 through 4, adolescents completed the emotional tone subscale from the Self-Image Questionnaire for Young Adolescents (Petersen, Schulenberg, Abramowitz, Offer, \& Jarcho, 1984). This subscale measures depressive 
and anxious affect, with 11 items (e.g., "I frequently feel sad"; "I am so very nervous"), rated on a 6-point scale ranging from 1 (does not describe me at all) to 6 (describes me very well). Mean scale scores were calculated so that higher scores indicated higher levels of negative affect. Cronbach's alpha across the four times of measurement ranged from .79 to .86 . Scores on this subscale were related significantly to other indices of internalizing problems such as depression, anxiety, and fears (Graber, Brooks-Gunn, Paikoff, \& Warren, 1994; Petersen et al., 1984).

\section{Results}

\section{Descriptive Statistics and Correlations}

Table 1 presents means, standard deviations, and intercorrelations for the measures of externalizing and internalizing problems, parenting behaviors, and association with deviant peers. On average, adolescents reported relatively low levels of externalizing problems and internalizing problems, and their peers were not highly involved in deviant behavior. Parents, on average, reported moderate to high levels of support and behavioral control and low to moderate levels of psychological control. Correlations show that parents who were more supportive used less psychological control. Higher behavioral control was associated consistently with lower levels of internalizing problems. Adolescents who reported more externalizing and internalizing problems tended to associate with peers who were more deviant. Stabilities for externalizing problems were generally moderately high across the five occasions. Internalizing problems also showed moderate stability across time.

\section{Effects of Parenting on Trajectories of Externalizing and Internalizing Problems}

The main data analysis used HLM (Bryk \& Raudenbusch, 1992; Mason, Wong, \& Entwistle, 1984), a method that allows simultaneous estimation of both (a) a separate within-person model of regression intercepts and slopes (i.e., growth trajectories) for each respondent, and (b) a betweenperson model in which the within-person slopes and intercepts are treated as dependent variables regressed on person-level predictor variables. It is important to point out that this estimation procedure takes into consideration the amount of data available from each person, so that more weight is given to persons with complete data than those with some missing data (Dempster, Laird, \& Rubin, 1977). Thus, instead of deleting all of the respondent's data

Table 1

Descriptive Statistics $(M, S D, n)$ for and Pearson Correlations Among Parenting Behaviors, Externalizing and Internalizing Problems, and Deviant Peers

\begin{tabular}{|c|c|c|c|c|c|c|c|c|c|c|c|c|c|c|c|c|c|c|c|c|}
\hline Measure & $M$ & $S D$ & $n$ & 1 & 2 & 3 & 4 & 5 & 6 & 7 & 8 & 9 & 10 & 11 & 12 & 13 & 14 & 15 & 16 & 17 \\
\hline 1. $\mathrm{SP}^{\mathrm{a}}$ & 3.74 & .38 & 109 & & & & & & & & & & & & & & & & & \\
\hline 2. $\mathrm{BC}^{\mathrm{a}}$ & 3.92 & .31 & 109 & 07 & & & & & & & & & & & & & & & & \\
\hline 3. $\mathrm{PC}^{\mathrm{a}}$ & 2.17 & .42 & 109 & $-29 *$ & -13 & & & & & & & & & & & & & & & \\
\hline 4. $\mathrm{EP}^{\mathrm{a}}(\mathrm{T} 1)$ & 1.18 & .19 & 107 & -11 & -14 & 13 & & & & & & & & & & & & & & \\
\hline 5. EP (T2) & 1.16 & .19 & 101 & -12 & 03 & $31^{*}$ & $55^{*}$ & & & & & & & & & & & & & \\
\hline 6. EP (T3) & 1.20 & .23 & 91 & 01 & 02 & 18 & $62 *$ & $59^{*}$ & & & & & & & & & & & & \\
\hline 7. EP (T4) & 1.29 & .33 & 77 & -05 & $-35^{*}$ & 08 & $56^{*}$ & $36^{*}$ & $27^{*}$ & & & & & & & & & & & \\
\hline 8. EP (T5) & 1.39 & .41 & 75 & -01 & -17 & 15 & $37^{*}$ & $48^{*}$ & 22 & $69 *$ & & & & & & & & & & \\
\hline 9. $\mathrm{IP}^{\mathrm{b}}(\mathrm{T} 1)$ & 2.45 & .84 & 108 & -07 & $-29 *$ & 17 & $24^{*}$ & 02 & 06 & 07 & -15 & & & & & & & & & \\
\hline 10. IP (T2) & 2.31 & .75 & 103 & -16 & -19 & 08 & $31 *$ & 12 & 10 & 22 & -06 & $57 *$ & & & & & & & & \\
\hline 11. IP (T3) & 2.42 & .89 & 90 & -18 & $-26^{*}$ & $24^{*}$ & 11 & -06 & -01 & $30 *$ & 18 & $53 *$ & $44^{*}$ & & & & & & & \\
\hline 12. IP (T4) & 2.42 & .86 & 74 & -21 & $-33^{*}$ & 18 & 14 & 06 & -12 & $32 *$ & 14 & $47^{*}$ & $43^{*}$ & $67^{*}$ & & & & & & \\
\hline 13. $\mathrm{DP}^{\mathrm{c}}(\mathrm{T} 1)$ & 1.74 & .65 & 109 & -00 & -16 & 14 & $43 *$ & $22^{*}$ & $28^{*}$ & $26^{*}$ & 14 & $29 *$ & $22 *$ & $29 *$ & 18 & & & & & \\
\hline 14. DP (T2) & 1.66 & .64 & 103 & -06 & $-28 *$ & 15 & $41 *$ & $34^{*}$ & $33^{*}$ & $29 *$ & $23^{*}$ & $39 *$ & $33^{*}$ & $33 *$ & 21 & $66^{*}$ & & & & \\
\hline 15. DP (T3) & 1.71 & .65 & 91 & -09 & -20 & 08 & $40 *$ & $33^{*}$ & $51 *$ & $35^{*}$ & 20 & $36^{*}$ & 15 & $38^{*}$ & 08 & $46^{*}$ & $48^{*}$ & & & \\
\hline 16. DP (T4) & 1.86 & .68 & 76 & -13 & $-27^{*}$ & 01 & $44^{*}$ & $42^{*}$ & 19 & $66^{*}$ & $47^{*}$ & 16 & $29 *$ & 20 & $36^{*}$ & $34^{*}$ & $35^{*}$ & $44^{*}$ & & \\
\hline 17. DP (T5) & 2.22 & .71 & 74 & 08 & -10 & -18 & $32 *$ & 22 & 11 & $50 *$ & $54^{*}$ & 03 & -01 & 06 & 07 & 08 & 15 & 18 & $39 *$ & \\
\hline
\end{tabular}

Note. $\mathrm{SP}=$ support; $\mathrm{BC}=$ behavioral control; $\mathrm{PC}=$ psychological control; $\mathrm{EP}=$ externalizing problems; $\mathrm{IP}=$ internalizing problems; $\mathrm{DP}=$ deviant peers; $\mathrm{T}=$ time. Decimal points are omitted from correlations.

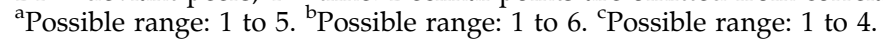
$* p<.05$. 
because of a missed questionnaire, this approach has the advantage of using all available data from a given respondent.

For illustrative purposes, the simple form of an HLM can be conceived of as two separate models, one a within-person model (Level 1) and the other a between-person model (Level 2). To begin, we fit a within-person model that assesses the individual trajectories of adolescent outcomes across the five occasions of measurement. This model can be expressed as:

$$
\begin{aligned}
& \text { Level 1: ADOLESCENT PROBLEMS } \\
& \qquad=\beta_{0 i}+\beta_{1 i}\left(\text { Time }_{t i}\right)+\mathrm{R}_{t i},
\end{aligned}
$$

where ADOLESCENT PROBLEMS ${ }_{t i}$ is the reported problem (i.e., externalizing or internalizing) of Adolescent $_{i}$ on Time ${ }_{t}$, Time ${ }_{t i}$ indicates the number of years from the beginning of the study, $\mathrm{B}_{0 i}$ is the intercept indicating Adolescent ${ }_{i}$ 's problem score at the initial time of measurement, $\mathrm{B}_{1 i}$ is the slope indicating the linear rate of change in problems of Adolescent $_{i}$, and $\mathrm{R}_{t i}$ is the random component or error associated with each adolescent's trajectory. To estimate average effects for the entire sample, the intercepts and slopes of the Level 1 within-person model become the outcomes for the Level 2 betweenperson equations, as follows:

$$
\begin{gathered}
\text { Level 2: } \beta_{0 i}=\pi_{00}+U_{0 i} \\
\beta_{1 i}=\pi_{10}+U_{0 i} .
\end{gathered}
$$

Equation 2 shows that Adolescent ${ }_{i}$ 's average problem score in Grade $6\left(\mathrm{~B}_{0 i}\right)$ is a function of the intercept for the entire sample - the grand mean of the sample - and a random component or error $\left(U_{0 i}\right)$. Likewise, Equation 3 shows that Adolescent ${ }_{i} \mathrm{~s}$ time slope $\left(B_{1 i}\right)$ is a function of the grand mean of the entire sample and a random component or error $\left(U_{0 i}\right)$.

The next step in the analyses assessed the extent to which initial levels and slopes are a function of parenting behaviors at the initial time of measurement. A distinctive feature of HLM is that the intercepts and slopes are allowed to vary across persons (Lee \& Bryk, 1989). Therefore, betweenperson models of within-person trajectories can be formulated.

To examine whether parenting behaviors are associated with adolescent trajectories of externalizing problems and internalizing problems, we fit the following model

$$
\begin{aligned}
& \text { Level 1: ADOLESCENT PROBLEMS } \\
& \quad=\beta_{0 i}+\beta_{1 i}\left(\text { Time }_{t i}\right)+\mathrm{R}_{t i}
\end{aligned}
$$

$$
\begin{aligned}
& \text { Level 2: } \beta_{0 i}=\pi_{00}+\pi_{01}(\mathrm{SUPPORT}) \\
& +\pi_{02} \text { (BEHAVIORAL CONTROL) } \\
& +\pi_{03}(\text { PSYCHOLOGICAL CONTROL) } \\
& +U_{0 i} \\
& \beta_{1 i}=\pi_{10}+\pi_{11} \text { (SUPPORT) } \\
& +\pi_{21} \text { (BEHAVIORAL CONTROL) } \\
& +\pi_{31}(\text { PSYCHOLOGICAL CONTROL })+U_{0 i} \text {. }
\end{aligned}
$$

The models in Equations 5 and 6 tested whether the initial level $\left(\mathrm{B}_{0 i}\right)$ and rate of change in adolescent behavior $\left(\mathrm{B}_{1 i}\right)$ varied according to parents' support, behavioral control and psychological control.

The initial HLM analyses explored a set of three models for externalizing problems and internalizing problems, respectively. All variables were grandmean centered to reduce cross-level confounding (Jaccard, Turrisi, \& Wan, 1990). Model 1 examined the average within-person rate of change in externalizing problems and internalizing problems across time (five waves for externalizing problems and four waves for internalizing problems). Model 2 tested the between-person differences in mean levels of externalizing and internalizing problems in Grade 6 and the average rate of change in these problems as a function of parenting behaviors. In Model 3 the three 2-way interactions among the three parenting behaviors were added as predictors of Grade 6 levels and rates of change in externalizing and internalizing problems.

The results for externalizing problems are presented in Table 2. In Model 1 there was a significant time effect. Adolescents increased their externalizing problems across the five waves of measurement. In examining between-person predictors in Model 2, none of the parenting variables were related to externalizing problems in Grade 6. Across time, however, behavioral control was related to externalizing problems. Adolescents whose parents used more behavioral control increased their engagement in externalizing problems at a slower rate, relative to adolescents whose parents were less behaviorally controlling. In Model 3, there was a significant main effect of psychological control on initial levels of externalizing problems. Adolescents whose parents used more psychological control reported more externalizing problems. However, this finding was qualified by the significant interaction between psychological control and behavioral control on initial levels of externalizing problems. 
Table 2

Multilevel Results of the Effects of Parenting Behaviors on Initial Level and Change in Externalizing Problems

\begin{tabular}{lccr}
\hline & Model 1 & Model 2 & Model 3 \\
\cline { 2 - 4 } Variable & Coefficient (SE) & Coefficient $(S E)$ & Coefficient (SE) \\
\hline EP in Grade 6 & $1.16(.02)^{*}$ & $1.15(.02)^{*}$ & $1.16(.02)^{*}$ \\
Support (SP) & & $-.02(.05)$ & $-.01(.05)$ \\
Behavioral control (BC) & & $.02(.07)$ & $-.00(.06)$ \\
Psychological control (PC) & & $.08(.06)$ & $.10(.05)^{*}$ \\
SP $\times$ BC & & $.19(.14)$ \\
SP $\times$ PC & & & $-.06(.12)$ \\
BC $\times$ PC & $.06(.01)^{*}$ & $.06(.01)^{*}$ & $.35(.16)^{*}$ \\
Rate of change in EP & & $.02(.02)$ & $.06(.01)^{*}$ \\
Support (SP) & & $-.10(.04)^{*}$ & $-.02(.03)$ \\
Behavioral control (BC) & & $.03(.04)$ & $.02(.04)^{*}$ \\
Psychological control (PC) & & & $-.02(.08)$ \\
SP $\times$ BC & & & $-.02(.07)$ \\
SP $\times$ PC & & & $-.11(.08)$ \\
BC $\times$ PC & & &
\end{tabular}

Note. EP = externalizing problems. Level $1 N=449$. Level $2 N=109$.

$* p<.05$.

Follow-up analyses showed that the effect of higher psychological control on higher initial levels of externalizing problems was limited to families in which the parents were also high on behavioral control, $B=.10, S E=.05, p<.05$. For families in which parents were low on behavioral control, there was no relationship between psychological control and externalizing problems, $B=.01, S E=.07, p>.05$.

Given that a goal of this study was to examine the relative and unique influence of support, behavioral control, and psychological control on adolescent adjustment, we calculated the proportion of between-person variance in the time slopes accounted for by each of the three parenting predictors, controlling for the other two parenting behaviors. To do so, we compared tau (the between-person variance in the slopes) for Model 2 with tau in three models. In each of the three models, one parenting behavior was removed (reduced model). The proportion of between-person variance in the time slopes accounted for by a specific parenting behavior was calculated as the difference between tau for Model 2 and tau for the reduced model, divided by tau for the reduced model (Nezlek, 2001). The results were that behavioral control explained $7.5 \%$ of the between-person variance in the time slopes, controlling for support and psychological control. Support and psychological control, however, each explained less than $1 \%$ of the variance in trajectories for externalizing problems, controlling for the other parenting behaviors. Thus, this conservative test of the relative and unique influence of three parenting behaviors on trajectories of externalizing problems confirmed the importance of behavioral control.

A different picture emerged for trajectories of internalizing problems (see Table 3). The results of Model 1 revealed that, on average, adolescents' internalizing problems did not change across time. Model 2 showed that parents' behavioral control in Grade 6 was significantly and negatively associated with Grade 6 levels of internalizing problems. Adolescents whose parents used more behavioral control had lower levels of internalizing problems. None of the main effects of parenting behaviors were related to internalizing problems across time. Nevertheless, we examined the relative and unique influence of the three parenting behaviors on between-person variance in the time slopes for internalizing problems (comparing tau for Model 2 in Table 3 with tau in reduced models in which the parenting behavior in question was removed). The results were that support explained $7 \%$ of the between-person variance in trajectories in internalizing problems, whereas behavioral control and psychological control explained $2.7 \%$ and $.6 \%$ of the variance, respectively.

We estimated a final model testing the curvilinear effects of behavioral control on initial levels and the trajectories of externalizing and internalizing problems. We squared the behavioral control variable and added it to Model 2. This quadratic term was 
Table 3

Multilevel Results of the Effects of Parenting Behaviors on Initial Level and Change in Internalizing Problems

\begin{tabular}{lccr}
\hline & Model 1 & Model 2 & \multicolumn{1}{c}{ Model 3 } \\
\cline { 2 - 4 } Variable & Coefficient (SE) & Coefficient $(S E)$ & Coefficient SE) \\
\hline IP in Grade 6 & $2.39(.07)^{*}$ & $2.39(.07)^{*}$ & $2.41(.07)^{*}$ \\
Support (SP) & & $-.14(.18)$ & $-.13(.19)$ \\
Behavioral control (BC) & & $-.60(.19)^{*}$ & $-.62(.19)^{*}$ \\
Psychological control (PC) & & $.22(.16)$ & $.24(.16)$ \\
SP $\times$ BC & & & $-.34(.44)$ \\
SP $\times$ PC & & & $.31(.38)$ \\
SP $\times$ PC & $-.01(.04)$ & $-.00(.04)$ & $-.02(.04)$ \\
Rate of change in IP & & $-.04(.11)$ & $-.07(.11)$ \\
Support (SP) & & $-.06(.11)$ & $-.02(.10)$ \\
Behavioral control (BC) & & $.05(.12)$ & $.02(.10)$ \\
Psychological control (PC) & & & $.38(.24)$ \\
SP $\times$ BC & & & $-.19(.25)$ \\
SP $\times$ PC & & & $-.41(.26)$ \\
BC $\times$ PC & & &
\end{tabular}

Note. IP = internalizing problems. Level $1 N=374$. Level $2 N=109$.

$* p<.05$.

not significant for either externalizing or internalizing problems.

\section{The Relative Effects of Parenting and Deviant Peers on Trajectories of Externalizing Problems}

The next set of analyses explored the influence of peers relative to parents for externalizing problems. All variables were grand-mean centered. Three models were tested. Results for externalizing problems are presented in Table 4. Model 1 examined between-person differences in initial levels and rates of change in externalizing problems as a function of the three parenting behaviors and deviant peers at Grade 6. Deviant peers in Grade 6 were found to be positively related to externalizing problems in Grade 6 , but not to rate of change in externalizing problems across time. Behavioral control was associated negatively with rate of change in externalizing problems such that the increase in externalizing was more rapid in adolescents with parents reporting less behavioral control.

In Model 2, the three 2-way interactions between deviant peers and each of the three parenting behaviors were added. New in this analysis was a significant interaction between deviant peers and behavioral control predicting rate of change in externalizing problems. The nature of this interaction was probed by conducting separate HLM analyses for each of four groups created by median splits on the variables of deviant peers and behav- ioral control: (a) high peer deviance/low behavioral control, (b) high peer deviance/high behavioral control, (c) low peer deviance/low behavioral control, and (d) low peer deviance/high behavioral control. The analyses examined for each of these four groups the rate of change in externalizing problems across time. Figure 1, based on coefficients generated in these models, depicts the nature of the interaction. Externalizing problems increased significantly in the high peer deviance/low behavioral control group ( $B=.09, S E=.04, p<.05)$, the low peer deviance/ low behavioral control group $(B=.07, S E=.03$, $p<.05)$, and the low peer deviance/high behavioral control group, $(B=.12, S E=.03, p<.05)$. However, there was no significant increase in the high peer deviance/high behavioral control group $(B=.02$, $S E=.03, p>.05$ ).

To explore this interaction further, contrasts were created that compared the high peer deviance/high behavioral control group with each of the other three groups (a total of three contrasts). An HLM analysis was then conducted with the three contrasts entered as predictors of both initial levels and rates of change in externalizing problems. With respect to initial levels, the results demonstrated that externalizing problems in Grade 6 were significantly higher in the high peer deviance/high behavioral control group than in the two groups with low peer deviance (when behavioral control was low, $B=-.16, S E=.04, p<.05$, and when behavioral control was high, $B=-.20, S E=.04, p<.05)$. 
Table 4

Multilevel Results of the Effects of Parenting and Deviant Peers in Grade 6, and Across-Time Deviant Peers on Initial Level and Change in Externalizing Problems

\begin{tabular}{|c|c|c|c|}
\hline & Model 1 & Model 2 & Model 3 \\
\hline Variable & Coefficient (SE) & Coefficient $(S E)$ & Coefficient $(S E)$ \\
\hline Externalizing problems in Grade 6 & $1.16(.02)^{*}$ & $1.16(.02)^{*}$ & $.91(.03)^{*}$ \\
\hline Support (SP) & $-.02(.04)$ & $-.02(.05)$ & $-.04(.03)$ \\
\hline Behavioral control (BC) & $.04(.06)$ & $.05(.06)$ & $.12(.04) *$ \\
\hline Psychological control (PC) & $.06(.05)$ & $.06(.05)$ & $.02(.04)$ \\
\hline Deviant peers (DP) in Grade 6 & $.10(.03)^{*}$ & $.10(.03)^{*}$ & \\
\hline $\mathrm{SP} \times \mathrm{DP}$ & & $-.02(.06)$ & \\
\hline $\mathrm{BC} \times \mathrm{DP}$ & & $-.01(.10)$ & \\
\hline $\mathrm{PC} \times \mathrm{DP}$ & & $-.02(.09)$ & \\
\hline Rate of change in externalizing & $.06(.01)^{*}$ & $.06(.01)^{*}$ & $.03(.01)^{*}$ \\
\hline Support (SP) & $.02(.02)$ & $.03(.02)$ & $.03(.02)$ \\
\hline Behavioral control (BC) & $-.10(.04)^{*}$ & $-.10(.03)^{*}$ & $-.08(.03)^{*}$ \\
\hline Psychological control (PC) & $.03(.04)$ & $.04(.04)$ & $.03(.03)$ \\
\hline Deviant peers (DP) Grade 6 & $-.01(.02)$ & $-.02(.02)$ & \\
\hline $\mathrm{DP} \times \mathrm{SP}$ & & $.02(.04)$ & \\
\hline $\mathrm{DP} \times \mathrm{BC}$ & & $-.12(.04)^{*}$ & \\
\hline $\mathrm{DP} \times \mathrm{PC}$ & & $.02(.03)$ & \\
\hline DP as a time-varying covariate & & & $.15(.02)^{*}$ \\
\hline
\end{tabular}

Note. Level $1 N=449$. Level $2 N=109$. $* p<.05$.

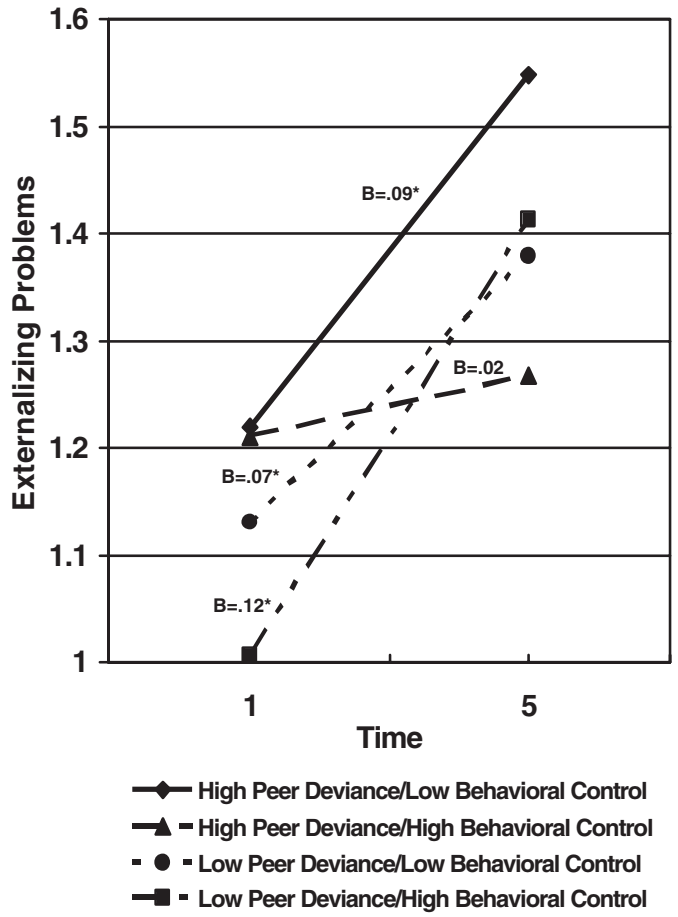

Figure 1. Trajectories of externalizing problems across five times of measurement as a function of Grade 6 levels of parental behavioral control and adolescents' association with deviant peers.
However, the third contrast was not significant, indicating that Grade 6 externalizing problems were similar in the two groups of adolescents with high peer deviance $(B=-.04, S E=.05, p>.05)$.

With respect to rates of change in externalizing problems, the contrasts showed that the slope for externalizing problems in the high peer deviance/ high behavioral control group was significantly different (i.e., flatter) from the slopes for the other three groups: high peer deviance/low behavioral control $(B=.13, S E=.03, p<.05)$, low peer deviance/low behavioral control $(B=.09, S E=.03$, $p<.05$ ), and low peer deviance/high behavioral control $(B=.09, S E=.03, p<.05)$. In short, although adolescents with deviant peers start out at a higher level on externalizing problems, and there is a general increase in externalizing problems across time, in only one group was this increase halted: the group of adolescents whose parents exerted higher levels of behavioral control in the face of their adolescents' higher association with deviant peers.

In Model 3 of Table 4, deviant peers was included at Level 1 as a time-varying covariate. This allowed us to test whether externalizing problems are higher when adolescents' peers are more deviant. This also allowed us to control for the influence of deviant 
peers across all five waves of measurement. Deviant peer association was related positively to more externalizing problems. More important though, the association between behavioral control and rate of change in externalizing problems remained significant even when controlling for the effect of deviant peers over time.

The Relative Effects of Parenting and Deviant Peers on Trajectories of Internalizing Problems

Table 5 presents the results for internalizing problems, which followed the analytic plan for examining the relative effects of parenting and deviant peers on externalizing problems. Model 1 examined the main effects of the three parenting behaviors and deviant peers, showing a significant negative association between behavioral control and Grade 6 levels of internalizing problems, as well as a positive relation between deviant peers and initial levels of internalizing problems. In Model 2 interactions between deviant peers at Grade 6 and the three parenting behaviors were added. None of the interactions were significant.

In Model 3, deviant peers was added to Model 1 at Level 1 as a time-varying covariate. That is, the effect of deviant peers at each wave of measurement was controlled. Association with more deviant peers was positively related to internalizing problems across time. After controlling for deviant peers at all four waves of measurement, the associations between behavioral control and Grade 6 internalizing problems remained significant.

\section{Follow-Up Analyses}

To examine whether controlling for gender would affect the results, all models in Tables 2 through 5 were recomputed, with gender entered as a covariate at Level 2. The inclusion of gender did not affect the pattern of results in any substantive manner. There was a main effect of gender on initial levels and rates of change in externalizing (but not internalizing) problems. Boys demonstrated higher levels of externalizing problems in Grade 6 than did girls, but girls accelerated faster over time compared with boys.

Given that the externalizing and internalizing problem scores were skewed, these scores were transformed using the natural logarithm. All analyses in Tables 2 through 5 were conducted again on the transformed scores. The results were virtually identical.

Table 5

Multilevel Results of the Effects of Parenting and Deviant Peers in Grade 6, and Across-Time Deviant Peers on Initial Level and Change in Internalizing Problems

\begin{tabular}{lccc}
\hline & Model 1 & Model 2 & Model 3 \\
\cline { 2 - 4 } Variable & Coefficient $(S E)$ & Coefficient $(S E)$ & Coefficient $(S E)$ \\
\hline Internalizing problems in Grade 6 & $2.39(.06)^{*}$ & $2.40(.07)^{*}$ & $1.93(.11)^{*}$ \\
Support (SP) & $-.16(.17)$ & $-.16(.17)$ & $-.11(.16)$ \\
Behavioral control (BC) & $-.51(.17)^{*}$ & $-.49(.17)^{*}$ & $-.49(.17)^{*}$ \\
Psychological control (PC) & $.17(.16)$ & $.18(.16)$ & $.18(.15)$ \\
Deviant peers (DP) in Grade 6 & $.29(.11)^{*}$ & $.28(.11)^{*}$ & \\
SP $\times$ DP & & $-.16(.26)$ & \\
BC $\times$ DP & & $-.18(.23)$ & $-.02(.04)$ \\
PC $\times$ DP & $-.00(.04)$ & $-.30(.24)$ & $-.04(.11)$ \\
Rate of change in internalizing & $-.04(.11)$ & $-.06(.13)$ & $.03(.11)$ \\
Support (SP) & $-.08(.11)$ & $-.10(.11)$ & \\
Behavioral control (BC) & $.06(.12)$ & $.05(.13)$ & \\
Psychological control (PC) & $-.06(.06)$ & $-.08(.06)$ & \\
Deviant peers (DP) Grade 6 & & $-.18(.24)$ & $.27(.06)^{*}$ \\
DP $\times$ SP & & $-.06(.13)$ & \\
DP $\times$ BC & & $.07(.16)$ & \\
DP $\times$ PC & & & \\
DP as a time-varying covariate & & & \\
\hline
\end{tabular}

Note. Level $1 N=374$. Level $2 N=109$.

$* p<.05$. 
We also tested for a quadratic slope in the trajectory of externalizing problems. The quadratic effect was significant, because the first three times of measurement were 6 months apart in early adolescence, after which the line accelerated. This effect was not included in the main analyses because power at Levels 1 and 2 was too limited to detect significance in the predictors of the quadratic trend.

Finally, the interaction presented in Figure 1 was puzzling. It was not surprising that externalizing problems remained stable in adolescents with deviant peers whose parents exerted high behavioral control. It was surprising, however, that externalizing problems increased in adolescents with low peer deviance and parents' high behavioral control. How can the difference between these two groups be explained? We speculated that high behavioral control by parents of adolescents with deviant peers might be more geared to monitoring their adolescents' friendships compared with parents who show high behavioral control in the relative absence of deviant peers. An examination of the items on the behavioral control scale reveals that this scale may not capture the specific behavior of monitoring adolescents' friendships. In Grade 6, however, adolescents completed an eight-item scale from the CRPBI (Schaefer, 1965), which was meant to measure intrusiveness, but was included in our study as a monitoring measure (e.g., "My parents keep a careful check on me to make sure that I have the right kind of friends"; "My parents want to know with whom I've been when I've been out"). Adolescents indicated the extent to which they agreed with each item on a scale from 1 (disagree strongly) to 4 (agree strongly; $\alpha=.81$ ). A nonsignificant correlation between behavioral control and monitoring confirmed that the two measures were orthogonal in this study, $r=.00, p>.05$. Furthermore, a $t$ test revealed significantly stronger perceptions of parent monitoring among adolescents in the high peer deviance/high behavioral control group $(M=2.54, S D=.60)$ compared with adolescents in the low peer deviance/high behavioral control group, $M=2.20, S D=.49, t(51)=2.30, p<.05$.

\section{Discussion}

This study examined (a) the relative influence of parental support, behavioral control, and psychological control and their interactions on adolescents' initial levels of and trajectories of change from early to middle adolescence in externalizing and internalizing problems; (b) the relative influence of parenting and deviant peers on adolescents' problems; and (c) curvilinear effects of behavioral control in predicting adolescents' initial problems and problem trajectories.

Which parenting behaviors predicted adolescents' initial (Grade 6) externalizing problems? Parents' higher levels of psychological control were related to adolescents' higher levels of externalizing problems but only when parents also reported higher behavioral control. This is an intriguing interaction, especially considering that psychological and behavioral control are typically inversely related (Barber, 1996). One possible explanation for this finding concerns child effects on parenting behaviors. Longitudinal studies show reductions in positive parenting behaviors and increases in negative control over time in response to children who demonstrate behavior problems (Pettit et al., 2001; Scaramella et al., 2002; Spieker, Larson, Lewis, Keller, \& Gilchrist, 1999; Stice \& Barrera, 1995). The coupling of high psychological and high behavioral control may indicate that a coercive situation has developed in which parents react to a misbehaving child by resorting to all available means of control.

Alternatively, based on findings that psychological control in adolescence may be anteceded by proactive parenting in childhood, Pettit et al. (2001) speculated that in an effort to prevent the occurrence of behavior problems, some parents engage in "overmanagement." The link between adolescents' externalizing problems and the combination of parents' high psychological and high behavioral control might indicate that these parents are overmanaging their young adolescents in a way that is developmentally inappropriate and intrusive. Parents who exert control over their adolescents' psychological and behavioral lives, whether these parenting behaviors are antedated by child misbehavior or by good intentions, might be issuing a "double whammy" from which the adolescent escapes by engaging in externalizing behaviors. Thus, behavioral control, which is generally understood to be a positive aspect of parenting, may not be uniformly effective when it is combined with other less desirable parenting behaviors. Given that there was no interaction between behavioral and psychological control in the prediction of trajectories of externalizing problems, it is difficult to know whether there are long-term implications of this combination of parenting behaviors. Naturally, it will be important in future research to replicate the interaction between psychological and behavioral control and, if confirmed, to uncover in longitudinal research its unfolding effects on adolescents. 
Behavioral control emerged as the sole significant parenting behavior related to trajectories of change in externalizing problems. The typical trajectory in early adolescence toward higher levels of externalizing behaviors (Moffitt, 1993; Simons et al., 2001) seemed to be slowed down for adolescents whose parents reported firm behavioral control (and accelerated for adolescents whose parents did not). These results converge with earlier research showing that, on the whole, parents' firm discipline and limitsetting behaviors may be key in preventing or reducing adolescents' involvement in risky, aggressive, or norm-violating activities (e.g., Barber et al., 1994; Mason et al., 1996; Miller et al., 1986).

How did parents' behavioral control operate in the context of deviant peers in explaining trajectories of change in adolescents' externalizing problems? Although deviant peers and externalizing problems were positively and significantly associated in Grade 6 , parents' behavioral control (and not deviant peers) predicted the rate of change in externalizing problems across time. Moreover, even when the significant relations between deviant peers and externalizing problems at each time of measurement were controlled (as a time-varying covariate), parents' behavioral control in Grade 6 still seemed to make a difference in the rate of change in externalizing behavior. Finally, an interaction between behavioral control and deviant peers suggested that the upward trajectory in externalizing problems among adolescents with deviant peers appeared to be halted if parents were higher on behavioral control. These results confirm that having deviant peers is a risk factor for engaging in externalizing behaviors, but parents may play a critical role in diminishing that risk.

It is interesting that adolescents with less deviant peers also showed increases in externalizing problems. It may be that these adolescents were engaged in adolescence-limited problem behavior (behaviors such as drinking and shoplifting that fade by the end of adolescence; Moffitt, 1993). According to Moffitt's (1993) maturity gap theory, the reason some adolescents engage in adolescence-limited problem behaviors is that they hope to attain the rewards associated with mature status (material goods, being seen to be mature by their peers) that they observe being obtained by antisocial teens. Thus, adolescents with less deviant peers might mimic the activities of the more antisocial peers with whom they are not close friends.

A puzzling issue is why parents' high behavioral control did not prevent an increase in externalizing problems among adolescents with low peer de- viance. If adolescents' close friends are norm abiding, parents might not be aware that their adolescents are at risk of engaging in problem behavior and might fail to exert the kind of behavioral control necessary to reduce that likelihood. Indeed, adolescents whose peers were less deviant in Grade 6 and whose parents reported high behavioral control reported their parents as engaging in less monitoring compared with adolescents whose peers were more deviant in Grade 6 and whose parents reported high behavioral control. Thus, the group of parents whose adolescents were most at risk (those with more deviant peers) and who engaged in high behavioral control and high monitoring were the parents who seem to have been effective in preventing the escalation of externalizing problems in their adolescents. The presence of deviant peers may serve as an important cue to parents. Research shows that parents who are concerned that their adolescents' friends are a negative influence make more active attempts to manage their adolescents' friendships (e.g., by communicating disapproval) than do parents who are unconcerned about their adolescents' friends (Tilton-Weaver \& Galambos, 2003).

How was parenting related to adolescents' internalizing problems? Parents' behavioral control was a significant predictor of initial levels of internalizing problems, with adolescents whose parents reported firm behavioral control showing lower levels of internalizing problems in Grade 6. Although psychological control is generally more strongly linked to internalizing symptoms than is behavioral control, associations between behavioral control and internalizing symptoms have been observed (e.g., Barber, 1996; Kurdek \& Fine, 1994). With respect to trajectories of change in internalizing problems, on average, adolescents' internalizing problems neither increased nor decreased across time, and no parenting behaviors attained significance in predicting individual trajectories. It is interesting that calculations for the amount of between-person variance in trajectories of internalizing explained by the three predictors showed that parental support accounted for the largest proportion (7\%), followed by behavioral control $(2.7 \%)$. Perhaps in a sample with more change in internalizing problems, the effect of parental support would be significant.

The lack of significance of psychological control for internalizing problems may be a measurement issue. Although the psychological control measure is reliable and valid (Schwarz et al., 1985), Barber (1996) developed a new scale to capture the properties of psychological control better. It is also possible 
that the scale used to measure internalizing problems was too narrow in focus to detect the effects of psychological control. In light of these considerations and the body of research linking psychological control with internalizing symptoms (Barber et al., 1994; Gray \& Steinberg, 1999), psychological control should be studied further.

It is noteworthy that deviant peer association was positively linked with internalizing problems in Grade 6, as well as at other times of measurement as shown through concurrent correlations. Although the relationship between deviant peers and externalizing problems is well established and often studied, these results suggest that it might be worthwhile to engage in efforts to understand better the link between deviant peers and internalizing problems. Indeed, Brendgen et al. (2000) found that adolescents with deviant friends were more depressed than adolescents with nondeviant friends. This result was attributed to several possibilities. First, adolescents who associate with deviant peers may have similar backgrounds, attitudes, and experiences that predispose them to depression (Elliott, Huizinga, \& Ageton, 1985; Kandel, 1978). Second, the friendships of adolescents with deviant peers may be less supportive, more conflictual, and more coercive than friendships among nondeviant adolescents (Marcus, 1996). Third, friends who show deviant behavior might mutually reinforce and encourage negative thinking about their lives (Brendgen et al., 2000). Thus, adolescents with deviant friends may bring some vulnerabilities to their friendships that could lead to or amplify internalizing symptoms.

Overall, how did the three parenting dimensions compare as unique predictors of adolescents' externalizing and internalizing problems? Behavioral control stood out as a significant predictor of change in externalizing problems from early to middle adolescence, even overriding the known strong relationship between deviant peers and externalizing problems. Psychological control, on the other hand, was expected to have a significant relationship with internalizing problems, but it did not, as described previously. It is surprising that parental support was not a significant predictor of externalizing or internalizing problems.

The absence of parental support effects might be attributable to the choice of dependent measures. That is, support has been linked most consistently with measures of adolescents' academic achievement as well as psychosocial well-being and competence (e.g., Barber et al., 2002; Eccles et al., 1997; Gray \& Steinberg, 1999; Herman et al.,
1997) - indicators of positive adjustment that were not included in the present study. Moreover, the finding that support paled in comparison with behavioral control in the prediction of externalizing problems is consistent with some other research (Herman et al., 1997). Support may contribute to enhanced psychological, social, and academic wellbeing, but when it comes to limiting troublesome behavior, behavioral control may be most effective. We expected parental support to be related to initial levels and trajectories of internalizing problems. It was not significantly related to either. It is interesting, however, that support did explain the largest portion of between-person variability in trajectories of internalizing problems. Had there been more change over time in internalizing problems and had the measurement of internalizing problems extended to age 15 rather than age 14 (as it did for externalizing problems), support might have emerged as significant.

Although one goal of this study was to examine the unique contributions of three parenting behaviors to adolescent problems, another goal was to examine their interaction. Only 1 of 12 tests for twoway interactions among the three parenting behaviors was significant (the Behavioral Control $\times$ Psychological Control interaction for initial levels of externalizing problems). This result is not surprising given that there is little evidence for consistent interactions in the literature. Likewise, no evidence was found for a curvilinear effect of behavioral control on initial levels and trajectories of change in externalizing and internalizing problems. Whether this lack of curvilinearity is due to differences among samples (this is the only such study involving twoearner families), different measures (other studies have typically measured behavioral control with different scales), or the genuine lack of deviations from linearity, we do not know. We believe, however, that it is important to examine curvilinearity in future research.

This study should be considered in light of its limitations. The small and selective nature of the sample-predominately White adolescents in twoearner families-limits the extent to which the results may be generalized. Indeed, these parents and their adolescents may function better on average than those in a more representative sample. Moreover, whereas some parenting behaviors, particularly behavioral control, emerged as significant, there is much unexplained variability in initial levels and trajectories of adolescents' problems. Parenting can contribute to important adolescent developments, but it is important to consider other processes 
as well, including genetic relationships; the individual characteristics and personalities of parents and adolescents; and attributes of the peer, family, neighborhood, and community contexts.

In general, the results of this study call for the need to consider a broad range of adolescent outcomes so that the specificity of parenting effects becomes clear. Future research could benefit from multiwave longitudinal investigations that follow parents and children across childhood and adolescence to determine not only how parenting contributes to changes in adolescents' adjustment, but how earlier child behavior shapes parenting. Parents do matter, but it is important to explore how, when, and in what contexts their behaviors have the most impact.

\section{References}

Barber, B. K. (1996). Parental psychological control: Revisiting a neglected construct. Child Development, 67, 3296-3319.

Barber, B. K. (1997). Adolescent socialization in context - The role of connection, regulation, and autonomy in the family. Journal of Adolescent Research, 12, 5-11.

Barber, B. K., Maughan, S. L., Olsen, J. A., \& Thomas, D. L. (2002, April). Parental support, psychological control, and behavioral control: Assessing the nature of effects. Paper presented at the Society for Research on Adolescence Meeting, New Orleans, LA.

Barber, B. K., \& Olsen, J. A. (1997). Socialization in context: Connection, regulation, and autonomy in the family, school, and neighborhood, and with peers. Journal of Adolescent Research, 12, 298-315.

Barber, B. K., Olsen, J. E., \& Shagle, S. C. (1994). Associations between parental psychological and behavioral control and youth internalized and externalized behaviors. Child Development, 65, 1120-1136.

Barnes, G. M., Reifman, A. S., Farrell, M. P., \& Dintcheff, B. A. (2000). The effects of parenting on the development of adolescent alcohol misuse: A six-wave latent growth model. Journal of Marriage and the Family, 62, 175-186.

Baumrind, D. (1991). Effective parenting during the adolescent transition. In P. A. Cowan \& M. Hetherington (Eds.), Family transitions (111-163). Hillsdale, NJ: Erlbaum.

Blishen, B. R., \& McRoberts, H. A. (1976). A revised socioeconomic index for occupations in Canada. Canadian Review of Sociology and Anthropology, 13, 71-79.

Brendgen, M., Vitaro, F., \& Bukowski, W. M. (2000). Deviant friends and early adolescents' emotional and behavioral adjustment. Journal of Research on Adolescence, 10, 173-189.

Brown, B. B., Clasen, D. R., \& Eicher, S. A. (1986). Perceptions of peer pressure, peer conformity disposi- tions, and self-reported behavior among adolescents. Developmental Psychology, 22, 521-530.

Bryk, A. S., \& Raudenbush, S. W. (1992). Hierarchical linear models: Applications and data analysis. Newbury Park, CA: Sage.

Burger, G. K., \& Armentrout, J. A. (1971). Comparative study of methods to estimate factor scores for reports of parental behaviors. Proceedings, $79^{\text {th }}$ Annual Convention, American Psychological Association, 6, 149-150.

Collins, W. A., Maccoby, E. E., Steinberg, L., Hetherington, E. M., \& Bornstein, M. H. (2000). Contemporary research on parenting: The case for nature and nurture. American Psychologist, 55, 218-232.

Costigan, C. L. (1996). Parental values related to control in families with children with special needs. Unpublished doctoral dissertation, Michigan State University.

Dempster, A. P., Laird, N. M., \& Rubin, D. B. (1977). Maximum likelihood from incomplete data via the EM algorithm. Journal of the Royal Statistical Society, Series B, $39,1-8$

Eccles, J. S., Early, D., Frasier, K., Belansky, E., \& McCarthy, K. (1997). The relation of connection, regulation, and support for autonomy to adolescents' functioning. Journal of Adolescent Research, 12, 263-286.

Elliott, D. S., Huizinga, D., \& Ageton, S. S. (1985). Explaining delinquent behavior and drug use. Beverly Hills, CA: Sage.

Fauber, R., Forehand, R., Thomas, A. M., \& Wierson, M. (1990). A mediational model of the impact of marital conflict on adolescent adjustment in intact and divorced families: The role of disrupted parenting. Child Development, 61, 1112-1123.

Forehand, R., \& Nousiainen, S. (1993). Maternal and paternal parenting: Critical dimensions in adolescent functioning. Journal of Family Psychology, 7, 213-221.

Galambos, N. L., \& Ehrenberg, M. F. (1997). The family as health risk and opportunity: A focus on divorce and working families. In J. Schulenberg, J. L. Maggs, \& K. Hurrelmann (Eds.), Health risks and developmental transitions during adolescence (pp. 139-160). Cambridge, England: Cambridge University Press.

Galambos, N. L., \& Maggs, J. L. (1991). Out-of-school care of young adolescents and self-reported behavior. Developmental Psychology, 27, 644-655.

Galambos, N. L., Sears, H. A., Almeida, D. M., \& Kolaric, G. C. (1995). Parents' work overload and problem behavior in young adolescents. Journal of Research on Adolescence, 5, 201-223.

Garber, J., Robinson, N. S., \& Valentiner, D. (1997). The relation between parenting and adolescent depression: Self-worth as a mediator. Journal of Adolescent Research, $12,12-33$.

Graber, J. A., Brooks-Gunn, J., Paikoff, R. L., \& Warren, M. P. (1994). Prediction of eating problems: An 8-year study of adolescent girls. Developmental Psychology, 30, 823-834.

Gray, M. R., \& Steinberg, L. (1999). Unpacking authoritative parenting: Reassessing a multidimensional construct. Journal of Marriage and the Family, 61, 574-587. 
Harris, J. R. (1995). Where is the child's environment? A group socialization theory of development. Psychological Review, 102, 458-489.

Herman, M. R., Dornbusch, S. M., Herron, M. C., \& Herting, J. R. (1997). The influence of family regulation, connection, and psychological autonomy on six measures of adolescent functioning. Journal of Adolescent Research, 12, 34-67.

Jaccard, J., Turrisi, R., \& Wan, C. K. (1990). Interaction effects in multiple regression. Newbury Park, CA: Sage.

Kandel, D. B. (1978). Similarity in real life adolescent pairs. Journal of Personality and Social Psychology, 36, 306-312.

Kaplan, H. B. (1978). Deviant behavior and self-enhancement in adolescence. Journal of Youth and Adolescence, 7, 253-277.

Kim, J. E., Hetherington, E. M., \& Reiss, D. (1999). Associations among family relationships, antisocial peers, and adolescents' externalizing behaviors: Gender and family type differences. Child Development, 70, 12091230.

Kurdek, L. A., \& Fine, M. A. (1994). Family acceptance and family control as predictors of adjustment in young adolescents: Linear, curvilinear, or interactive effects? Child Development, 65, 1137-1146.

Kurdek, L. A., Fine, M. A., \& Sinclair, R. J. (1995). School adjustment in sixth graders: Parenting transitions, family climate, and peer norm effects. Child Development, 66, 430-445.

Lamborn, S. D., Mounts, N. S., Steinberg, L., \& Dornbusch, S. M. (1991). Patterns of competence and adjustment among adolescents from authoritative, authoritarian, indulgent, and neglectful families. Child Development, 62, 1049-1065.

Lee, V. E., \& Bryk, A. S. (1989). A multilevel model of the social distribution of high school achievement. Sociology of Education, 62, 172-192.

Maccoby, E. E., \& Martin, J. A. (1983). Socialization in the context of the family: Parent-child interaction. In M. Hetherington (Ed.), Handbook of child psychology: Vol. 4. Socialization, personality, and social development (pp. 1101). New York: Wiley.

Maggs, J. L., Almeida, D. M., \& Galambos, N. L. (1995). Risky business: The paradoxical meaning of problem behavior for young adolescents. Journal of Early Adolescence, 15, 344-362.

Marcus, R. F. (1996). The friendships of delinquents. Adolescence, 21, 145-158.

Mason, C. A., Cauce, A. M., Gonzales, N., \& Hiraga, Y. (1996). Neither too sweet nor too sour: Problem peers, maternal control, and problem behavior in African American adolescents. Child Development, 67, 2115-2130.

Mason, W. M., Wong, G. Y., \& Entwisle, B. (1984). Contextual analysis through multilevel linear analysis. In S. Leinhardt (Ed.), Sociological methodology 1983-1984 (pp. 72-103). San Francisco: Jossey-Bass.

Miller, B. C., McCoy, J. K., Olson, T. D., \& Wallace, C. M. (1986). Parental discipline and control attempts in relation to adolescent sexual attitudes and behavior. Journal of Marriage and the Family, 48, 503-512.

Moffitt, T. E. (1993). Adolescence-limited and life-coursepersistent antisocial behavior: A developmental taxonomy. Psychological Review, 100, 674-701.

Nezlek, J. B. (2001). Multilevel random coefficient analyses of event- and interval-contingent data in social and personality psychology research. Personality and Social Psychology Bulletin, 27, 771-785.

Petersen, A. C., Compas, B. E., Brooks-Gunn, J., Stemmler, M., Ey, S., \& Grant, K. E. (1993). Depression in adolescence. American Psychologist, 48, 155-168.

Petersen, A. C., Schulenberg, J. E., Abramowitz, R. H., Offer, D., \& Jarcho, H. D. (1984). A Self-Image Questionnaire for Young Adolescents (SIQYA): Reliability and validity studies. Journal of Youth and Adolescence, 13, 93-111.

Pettit, G. S., Laird, R. D., Dodge, K. A., Bates, J. E., \& Criss, M. M. (2001). Antecedents and behavior-problem outcomes of parental monitoring and psychological control in early adolescence. Child Development, 72, 583-598.

Rollins, B. C., \& Thomas, D. L. (1979). Parental support, power, and control techniques in the socialization of children. In W. R. Burr, R. Hill, F. I. Nye, \& I. L. Reiss (Eds.), Contemporary theories about the family (Vol. 1, pp. 317-364). New York: Free Press.

Scaramella, L. V., Conger, R. D., Spoth, R., \& Simons, R. L. (2002). Evaluation of a social contextual model of delinquency: A cross-study replication. Child Development, 73, 175-195.

Schaefer, E. (1965). Children's reports of parental behavior: An inventory. Child Development, 36, 413-424.

Schwarz, J. C., Barton-Henry, M. L., \& Pruzinsky, T. (1985). Assessing child-rearing behaviors: A comparison of ratings made by mother, father, child, and sibling on the CRPBI. Child Development, 56, 462-479.

Simons, R. L., Chao, W., Conger, R. D., \& Elder, G. H., Jr. (2001). Quality of parenting as mediator of the effect of childhood defiance on adolescent friendship choices and delinquency: A growth curve analysis. Journal of Marriage and the Family, 63, 63-79.

Slicker, E. K. (1998). Relationship of parenting style to behavioral adjustment in graduating high school seniors. Journal of Youth and Adolescence, 27, 345-372.

Spieker, S. J., Larson, N. C., Lewis, S. M., Keller, T. E., \& Gilchrist, L. (1999). Developmental trajectories of disruptive behavior problems in preschool children of adolescent mothers. Child Development, 70, 443-458.

Steinberg, L., Lamborn, S. D., Darling, N., Mounts, N. S., \& Dornbusch, S. M. (1994). Over-time changes in adjustment and competence among adolescents from authoritative, authoritarian, indulgent, and neglectful families. Child Development, 65, 754-770.

Stice, E., \& Barrera, M., Jr. (1995). A longitudinal examination of the reciprocal relations between perceived parenting and adolescents' substance use and externalizing behaviors. Developmental Psychology, 31, 322-334. 
Stice, E., Barrera, M., Jr., \& Chassin, L. (1993). Relation of parental support and control of adolescents' externalizing symptomatology and substance use: A longitudinal examination of curvilinear effects. Journal of Abnormal Child Psychology, 21, 609-629.

Tilton-Weaver, L. C., \& Galambos, N. L. (2003). Adolescents' characteristics and parents' beliefs as predictors of parents' peer management behaviors. Manuscript submitted for publication.

Willett, J. B. (1989). Some results on reliability for the longitudinal measurement of change: Implications for the design of studies of individual growth. Educational and Psychological Measurement, 49, 587-602. 